\title{
Dilip V. Jeste, MD, on the state of psychiatry
}

Awais Aftab, MD, and Dilip V. Jeste, MD

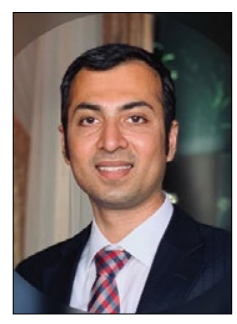

Awais Aftab, MD

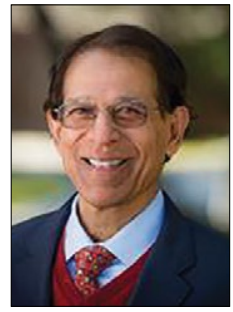

Dilip V. Jeste, MD
Editor's note: Psychiatry Leaders' Perspectives is a new department in CURRENT PSYCHIATRY in which we interview a prominent psychiatrist about the strengths, weaknesses, opportunities, and threats facing the field of psychiatry.

$n$ this first Psychiatry Leaders' Perspectives, Awais Aftab, MD, interviewed Dilip V. Jeste, MD. Dr. Jeste is Senior Associate Dean for Healthy Aging and Senior Care, Estelle and Edgar Levi Memorial Chair in Aging, Director of the Sam and Rose Stein Institute for Research on Aging, Distinguished Professor of Psychiatry and Neurosciences, University of California San Diego; and Co-Director of the UC San Diego-IBM Center on Artificial Intelligence for Healthy Living. His main areas of research include schizophrenia, neuropsychiatric interventions, and successful aging. He served as the 139th President of the American Psychiatric Association (APA) and also is a past president of the American Association for Geriatric Psychiatry, the West Coast College of Biological Psychiatry, and founding president of International College of Geriatric Psychoneuropharmacology.

Dr. Aftab: The focus of your term as president of the APA was on "positive psychiatry." You are also one of the world's foremost experts in this area. How successful have you been in your mission to promote positive psychiatry, and how has your message been received?

Dr. Jeste: Let me start with a little bit of background about why I got into positive psychiatry. As a geriatric psychiatrist, my research work has brought me face to face with the paradox of aging: although physical health declines with age, mental health and well-being improve on average. This is the case not just for individuals in the community but also for individuals with serious mental illnesses. That got me into thinking more and more about the ways in which we can bring positive change in the lives of patients. When I became the president of the APA, one of my main tasks was to finalize and publish the DSM-5, which rightly focuses on the disorders we treat, but it also provided me with an opportunity to highlight the side of psychiatry that focuses on the positive aspects of our own and our patients' lives, such as wisdom, resilience, meaning, and social connectedness.

As is the case with any new idea, there is a lot of resistance in the beginning and this will always be the case. However, I would say that positive psychiatry has been received very well. We now have an APA Caucus and a World Psychiatric Association Section on positive psychiatry. Our book, Positive Psychiatry, turned out to be one of the best sellers for American Psychiatric Publishing! Every year, there are symposia on positive

Dr. Aftab is Clinical Assistant Professor, Psychiatry, Case Western Reserve University, Cleveland, Ohio. Dr. Jeste is Senior Associate Dean for Healthy Aging and Senior Care, Estelle and Edgar Levi Memorial Chair in Aging, Director of the Sam and Rose Stein Institute for Research on Aging, Distinguished Professor of Psychiatry and Neurosciences, University of California San Diego; and Co-Director of the UC San Diego-IBM Center on Artificial Intelligence for Healthy Living.

Disclosures

The authors report no financial relationships with any companies whose products are mentioned in this article, or with manufacturers of competing products.

doi: 10.12788/cp.0057 
psychiatry and papers and books from other countries. Overall, the reception has been very promising.

Dr. Aftab: Thank you for this interesting background, Dr. Jeste. Now let me ask you about the current state of psychiatry. What do you see as some of the strengths of our profession?

Dr. Jeste: Psychiatry's unique strength is our skill in promoting adaptive behavior change, with a focus on positive factors such as resilience, wisdom, optimism, social engagement, improved health, and longevity. If you look at the research literature, the effect sizes of factors such as optimism, resilience, and social engagement are equal to or greater than interventions such as statins, smoking cessation, and exercise. Cardiothoracic surgeons and radiologists can't help people increase their resilience, optimism, and social engagement, but psychiatrists can. Behavior change is our expertise. When people are suicidal, we give them hope; we help depressed individuals become active, productive, and happy. We treat people with schizophrenia and bipolar disorder, reduce their psychopathological behaviors, and improve their everyday functioning.

Dr. Aftab: Are there ways in which the status quo in psychiatry falls short of the ideal? What are our areas of relative weakness?

Dr. Jeste: Unfortunately, there are a lot of restrictions posed by the current reimbursement system. As a result, psychiatrists spend most of their time prescribing medications in clinical practice. I have nothing against psychopharmacology, but we also need to focus on important aspects of our lives, such as lifestyle, cognitive attitudes, self-care, and social engagement. We need to go beyond symptom reduction. A prominent example is loneliness, which is a major risk factor for morbidity and mortality; the treatment for loneliness is not increasing social network, it's actually changing one's perception of and ability to enhance appropriate socialization. Who can do that? Psychiatrists! But we don't do that right now because the health insurance system doesn't reimburse psychiatrists to do that.

Dr. Aftab: What is your perception of the threats that psychiatry faces? You had to fend off a variety of challenges during your year as APA president, such as issues surrounding revision of DSM-5. How has that experience shaped your assessment?

Dr. Jeste: I was honored to oversee the finalization and publication of DSM-5 as the president of the APA, even though I lost a lot of sleep working on it! What I found was that there was a lot of antagonism in the media, as well as among several advocacy groups, about the DSM. The misperception was that psychiatry and the APA were trying to expand diagnoses so that the drug companies could sell medications to more people, and psychiatry would benefit from this because of its relationship with the industry. That was actually not the case at all. What I tried to do was to understand where these groups were coming from, and to treat them as collaborators and partners, not as enemies. One thing I am particularly proud of is that we established the Summit Group for DSM-5, which brought together perspectives of the various stakeholders, and our communication both within and outside of the APA improved significantly. It's gratifying to note that much of the controversy in the media died down after DSM-5 was published. The often-critical New York Times wrote that while DSM-5 is far from perfect, it is the best we have today clinically, and I'm very proud of the work we did on it.

Dr. Aftab: What sort of opportunities lie ahead for psychiatry? What do you envision for the future of the field?

\section{Clinical Point}

'I have nothing against psychopharmacology, but ... we need to go beyond symptom reduction.'

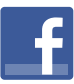

Discuss this article at www.facebook.com/ MDedgePsychiatry 
Clinical Point

'The effects of

psychosocial

interventions such

as meditation and

long-term CBT on

the brain are now

indisputable.'
Dr. Jeste: As a neuroscientist, I'm excited about the new developments in brain science. Our understanding of the neurobiologic basis of mental illnesses is slowly but surely increasing. I'm also very heartened by all the research going on with regard to the prevention of mental illnesses. I think we will be able to reduce the risk of many psychiatric disorders in the future. This is an exciting time for the field, and psychiatry is going to look very different 20 years from now!

Dr. Aftab: Some people think there's a conflict between a neuroscientific and psychosocial understanding of psychiatry. How do you think the 2 relate to each other?

Dr. Jeste: The reality, I think, is that there is no conflict. Ultimately, the mind is a function of the brain, and the mind operates within a society. Neuroscientists are also realizing the importance of psychosocial aspects, and there is a growing social neuroscience, looking at the neurobiology of things such as loneliness, social isolation, and wisdom. The effects of psychosocial interventions such as meditation and long-term cognitivebehavioral therapy on the brain are now indisputable. I like to say that psychosocial interventions are often more biological in their effects than the drugs!

Dr. Aftab: Any words of wisdom for psychiatry trainees and early career psychiatrists?

Dr. Jeste: First of all, I congratulate them for going into psychiatry, which is rapidly advancing and is the field of the future. Looking at new developments, such as in artificial intelligence, I wish I could be a young person again just getting into psychiatry! The role of psychiatrists is also evolving, and psychiatrists will become leaders of multidisciplinary teams. I would advise trainees and early career psychiatrists not to get frustrated by issues such as insurance reimbursements; these obstacles will pass. Society is becoming far more conscious of the importance of mental health to our wellbeing. So I see a reason to be optimistic. I would also mention that the younger generation has a lot to teach the older generation while at the same time benefitting from the wisdom they have to offer. One of the best things we can promote is intergenerational activity, both within and outside of our profession. 